Linda Collins MB BCH BAO FFARCSI, * James Prentice MD FRCPC, * Himat Vaghadia MB BS FRCPC MHSC* $\dagger$

\section{Tracheal intubation of outpatients with and without muscle relaxants}

Purpose: To compare intubating conditions and postoperative myalgias in outpatients after intubation with propofol/alfentanil compared with propofol/alfentanil/succinylcholine with and without precurarisation with d-tubocurarine.

Methods: I44 ASA I - II ambulatory patients for dental extraction under anesthesia were studied. Subjects received either 3mg d-tubocurarine (Group II) or saline (Groups I, III) iv prior to induction of anesthesia with 20 $\mu \mathrm{g} \cdot \mathrm{kg}^{-1}$ alfentanil and $2.5 \mathrm{mg} \cdot \mathrm{kg}^{-1}$ propofol followed by $1.5 \mathrm{mg} \cdot \mathrm{kg}^{-1}$ succinylcholine (II and III) or saline $0.9 \%$ (I) for muscle relaxation. The ease of airway management and the postoperative incidence, severity and distribution of muscle pains were examined.

Results: Intubation was successful in all patients and there were no differences in jaw mobility, ease of bag-mask ventilation, visualization of the vocal cords or cord position. Limb movement was more common during intubation in Group I (37.5\%) than in Group III (8.3\%) or Group II (2\%), P< 0.05. At home, VAS scores for myalgia were higher in Group III than in Group I and II. Neck myalgia was more common in Group III (72\%) than in Groups II (44\%) and I (4 I\%), $P<0.05$. Myalgias were also more common in Group III patients $(P<0.05)$.

Conclusion: Acceptable intubating conditions were achieved with propofol and alfentanil alone. Succinylcholine reduced limb movement during intubation but was associated with postoperative myalgias for up to five days. Precurarisation with tubocurarine reduced the severity of succinylcholine myalgia.

Objectif : Comparer, chez des patients ambulatoires, les conditions d'intubation et les myalgies postopératoires qui ont suivi une intubation avec propofol / alfentanil, ou propofol / alfentanil / succinylcholine, avec ou sans précurarisation avec de la d-tubocurarine.

Méthode : L'étude a porté sur 144 patients ambulatoires, d'état physique ASA I - II, admis pour extraction dentaire. Les sujets ont reçu $3 \mathrm{mg}$ de d-tubocurarine (Groupe II) ou de solution salée (Groupes I, III) iv avant l'induction de l'anesthésie avec $20 \mu \mathrm{g} \cdot \mathrm{kg}^{-1}$ d'alfentanil et $2,5 \mathrm{mg} \cdot \mathrm{kg}^{-1}$ de propofol suivis de $1,5 \mathrm{mg} \cdot \mathrm{kg}^{-1}$ de succinylcholine (II et III), comme myorelaxant, ou de solution salée à 0,9\% (I). La facilité d'intubation et l'incidence postopératoire, la sévérité et la distribution des douleurs musculaires ont été examinées.

Résultats : L'intubation a réussi chez tous les patients. II n'y a pas eu de différence concernant la mobilité de la mâchoire, la facilité de ventilation au masque, la visualisation des cordes vocales ou leur position. Les mouvements des membres étaient plus fréquents à l'intubation chez les patients du Groupe I (37,5 \%) que des Groupes III (8,3 $\%)$ et II (2\%), $P<0,05$. Après le congé, les scores de myalgie à l'EVA étaient plus hauts dans le Groupe III que dans les Groupes I et II. La myalgie du cou a été plus fréquente dans le Groupe III (72 \%) que dans les Groupes II (44 \%) et I (4I \%), $P<0,05$. Les myalgies ont été aussi plus fréquentes dans le Groupe III $(P<0,05)$.

Conclusion : L'emploi de propofol / alfentanil seul a permis des conditions d'intubation acceptables. La succinylcholine a diminué les mouvements des membres pendant l'intubation, mais a été associée à des myalgies jusqu'à cinq jours après l'opération. La précurarisation avec la tubocurarine a réduit la sévérité de la myalgie reliée à la succinylcholine.

From the Departments of Anaesthesia* and Health Care and Epidemiology, $\uparrow$ Vancouver General Hospital, University of British Columbia, Vancouver, BC, Canada. Address correspondence to: Dr. Himat Vaghadia, Department of Anesthesia (LSP2449), Vancouver Hospital and Health Science Centre, 910 West 10th Avenue, Vancouver, B.C. V5Z 4E3 Canada. Phone: 604-875-4304; Fax: 604-875-5209; E-mail: hvaghadi@vanhosp.bc.ca Accepted for publication January 20, 2000. 
I $\mathrm{N}$ outpatients, the trachea may be intubated without the use of muscle relaxants. ${ }^{1-2}$ Intubating conditions with propofol and short acting opoids such as remifentanil ${ }^{2}$ and alfentanil $^{1}$ were described as satisfactory. However, these studies did not identify any other associated advantages of avoiding muscle relaxation. The rationale for avoiding muscle relaxants is also not obvious from such studies. One potential advantage to outpatients may be a reduced risk of side effects such as myalgia.

We therefore, studied intubating conditions and the incidence and distribution of myalgias in patients intubated with propofol / alfentanil compared to propofol / alfentanil/ succinylcholine (sux) with and without precurarisation.

Methods

After obtaining institutional ethics committee approval and written informed consent, 144 healthy ASA I and II patients undergoing dental surgery in the surgical day unit were enrolled in this double blinded study. Exclusion criteria included ASA III or greater, Mallampatti ${ }^{3}$ class IV, and known sensitivity to any agent used in the study. The patients were randomly assigned to one of three groups (Table I). Before induction all patients were sedated with 0.05 $\mathrm{mg} \cdot \mathrm{kg}^{-1}$ propofol so that the investigator would be blinded to the effects of saline or d-tubocurarine given subsequently for precurarisation as shown below. Anesthesia induction in all groups was identical: 20 $\mu \mathrm{g} \cdot \mathrm{kg}^{-1}$ alfentanil and $2.5 \mathrm{mg} \cdot \mathrm{kg}^{-1}$ propofol. The main differences between the groups were:

Group I (saline-saline): Subjects received saline for precurarisation and saline for intubation.

Group II (dTc- succ): Subjects received $3 \mathrm{mg}$ dtubocurarine for precurarisation and $1.5 \mathrm{mg} \cdot \mathrm{kg}^{-1}$ for intubation.

Group III (saline-sux): Subjects received saline for precurarisation and $1.5 \mathrm{mg} \cdot \mathrm{kg}^{-1}$ succinylcholine for intubation.

One minute after administration of relaxant or saline, the ease of mask ventilation (easy or difficult), jaw mobility (mobile or partly mobile), vocal cord visualization at laryngoscopy (full, partial or no exposure), position of the cords at intubation (open, midopen or closed), and movement of patients on intubation (yes or no) were recorded (Table III) simultaneously with intubation. The patients were then intubated nasally by direct laryngoscopy - blind nasal intubation was not performed in any patient. Anesthesia was maintained with $\mathrm{O}_{2} 40 \%$ in $\mathrm{N}_{2} \mathrm{O}$ and varying concentrations of isoflurane. Breathing was assisted until spontaneous ventilation returned. Anesthesia was administered by one anesthesiologist (J.P.) who remained blind to the group assignments. All drugs were prepared by a staff anesthesiologist not involved with the study to keep the study investigator blinded. Study drugs were prepared in identical syringes and in identical volumes. In the post anaesthetic room (PAR), the patients were asked by the same blinded anesthesiologist to indicate their degree of muscle pain using the visual analogue scale (VAS) anchored at 0 (no myalgia) and 10 (maximum myalgia) and, if present, to show diagramatically the location of their pain. All VAS assessments were performed when the patients were alert and oriented. All patients were followed for five days after surgery and asked to score their degree of muscle pain (VAS) at 24,48 and $72 \mathrm{hr}$ postoperatively. The postoperative questionnaire was returned by mail to the investigator.

\section{Statistical analysis}

Categorical data were expressed as counts or percentages and analyzed using chi-square and Fisher's exact tests as appropriate. Bonferroni's correction was used for multiple comparisons. Some categories had to be combined to increase small cell sizes for some variables. VAS myalgia in the PAR had to be condensed to categorical Yes/No data due to excessive numbers of zeros in its distributions. Most of the continuous data was skewed and so medians and ranges were used to summarize these variables. Between group comparisons were done using Kruskal-Wallis tests with Dunn's procedure post hoc if a significant difference

TABLE I Group assignment

\begin{tabular}{llll}
\hline & Group I & Group II & Group III \\
\hline Sedation & Propofol $0.05 \mathrm{mg} \cdot \mathrm{kg}^{-1}$ & Propofol $0.05 \mathrm{mg} \cdot \mathrm{kg}^{-1}$ & Propofol $0.05 \mathrm{mg} \cdot \mathrm{kg}^{-1}$ \\
Precurarization & Placebo & d-tubocurarine $3 \mathrm{mg}$ & Placebo \\
Delay & 3 min & 3 min & $3 \mathrm{~min}$ \\
Induction & Propofol $2.5 \mathrm{mg} \cdot \mathrm{kg}^{-1}$ & Propofol $2.5 \mathrm{mg} \cdot \mathrm{kg}^{-1}$ & Propofol $2.5 \mathrm{mg} \cdot \mathrm{kg}^{-1}$ \\
Induction & Alfentanil $20 \mu \mathrm{gg} \cdot \mathrm{kg}^{-1}$ & Alfentanil $20 \mu \mathrm{g} \cdot \mathrm{kg}^{-1}$ & Alfentanil $20 \mu \mathrm{g} \cdot \mathrm{kg}^{-1}$ \\
Delay & 1 min & 1 min & $1 \mathrm{~min}$ \\
Relaxant & Placebo & Succinylcholine $1.5 \mathrm{mg} \cdot \mathrm{kg}^{-1}$ & Succinylcholine $1.5 \mathrm{mg} \cdot \mathrm{kg}^{-1}$ \\
\hline
\end{tabular}


TABLE II Demographics: median (range) \& counts or $\%$

\begin{tabular}{lllll}
\hline & $\begin{array}{l}\text { Group I } \\
n=48\end{array}$ & $\begin{array}{l}\text { Group II } \\
n=48\end{array}$ & $\begin{array}{l}\text { Group III } \\
n=48\end{array}$ & $P$ \\
\hline $\begin{array}{l}\text { Age (yr) } \\
\text { (range) }\end{array}$ & $21(14-42)$ & $21(15-33)$ & $21(15-44)$ & .441 \\
M / F & $22 / 26$ & $15 / 33$ & $22 / 26$ & .244 \\
$\begin{array}{l}\text { Wt (kg) } \\
\text { (range) }\end{array}$ & $62(41-140)$ & $62(45-90)$ & $65(44-136)$ & .339 \\
$\begin{array}{l}\text { Mallampatti } \\
\text { Grade }\end{array}$ & $63 / 33 / 4$ & $75 / 19 / 6$ & $58 / 31 / 10$ & .203 \\
$1 / 2 / 3(\%)$ & & & \\
\hline
\end{tabular}

TABLE III Intubating conditions

\begin{tabular}{llll}
\hline & $\begin{array}{l}\text { Group I } \\
n=48\end{array}$ & $\begin{array}{l}\text { Group II } \\
n=48\end{array}$ & $\begin{array}{l}\text { Group III } \\
n=48\end{array}$ \\
\hline Jaw mobility & 92 & 98 & 92 \\
$\quad \begin{array}{l}\text { Mobile } \\
\text { Partly mobile }\end{array}$ & 8 & 2 & 8 \\
$\begin{array}{lll}\text { Mask ventilation } \\
\quad \text { Easy }\end{array}$ & 98 & 98 & 94 \\
$\quad$ Difficult & 2 & 2 & 6 \\
Exposure of vocal cords & & & \\
$\quad$ Full & 88 & 96 & 94 \\
$\quad \begin{array}{l}\text { Partial } \\
\text { No exposure }\end{array}$ & 10 & 2 & 6 \\
Vocal cord position & 2 & 2 & 0 \\
$\quad$ Open & 84 & 87 & 90 \\
$\quad \begin{array}{l}\text { Mid-open } \\
\text { Closed }\end{array}$ & 10 & 13 & 10 \\
Movement on intubation * & 6 & 0 & 0 \\
$\quad$ Yes & 37.5 & 2 & 8.3 \\
$\quad$ No & 62.5 & 98 & 91.7 \\
\hline
\end{tabular}

Values expressed as \%

${ }^{*} P<0.05$ (Group I vs II and III)

was found. $P<0.05$ was considered significant except where Bonferroni's correction was used. A power analysis was performed while designing the study. Allowing for an $\alpha$ of 0.05 and a $\beta$ of 0.2 it was estimated that a minimum number of 40 patients per group would be required to show a difference of $25 \%$ in the incidence of myalgia (control $=70 \%$ ).

\section{Results}

One hundred forty-four patients agreed to participate in the study. Of these, 123 returned the postoperative questionnaires by mail ( $85 \%$ response rate). There were no differences between groups in terms of sexistribution, weight, age or airway classification according to Mallampatti grades ${ }^{3}$ at laryngoscopy (Table II). Also, no differences were found in jaw mobility, ease of bag-mask ventilation, ability to visualize the vocal
TABLE IV VAS Scores: Median (range)

\begin{tabular}{llll}
\hline & Group I & Group II & Group III \\
\hline Day l VAS & $0.4(0-10) \dagger$ & $0.85(0-7.7) *$ & $2.7(0-10.3)$ \\
Day 2 VAS & $0.7(0-10) \dagger$ & $1.1(0-6.2) *$ & $3(0-9.8)$ \\
Day 3 VAS & $0(0-10.2)$ & $0(0-4.5) *$ & $1.4(0-9)$ \\
Day 4 VAS & $0(0-6.3)$ & $0(0-2.6) *$ & $0(0-9)$ \\
Day 5 VAS & $0(0-5)$ & $0(0-1.6)$ & $0(0-5.9)$ \\
\hline
\end{tabular}

* $P<0.05$ Group III vs II

$\dagger P<0.05$ Group III $v$ I

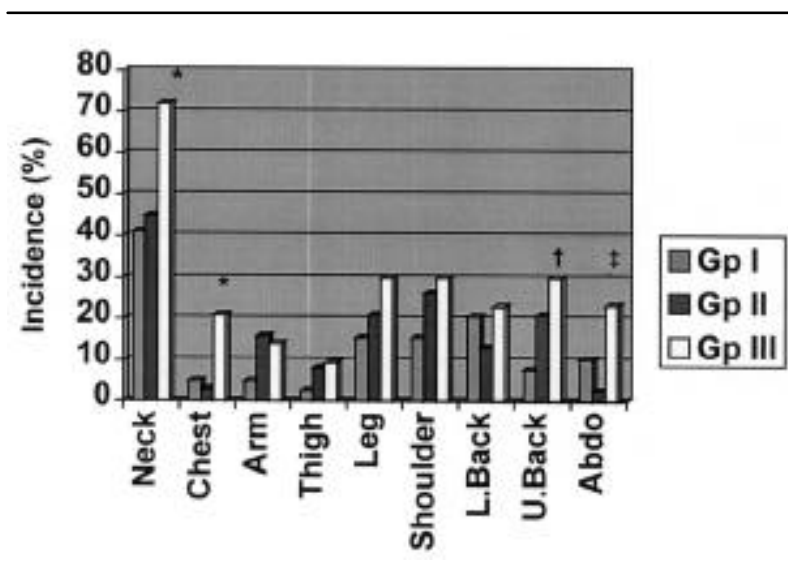

FIGURE 1 Incidence of myalgias at home by muscle group.

(L.Back = lower back; U.Back = upper back).

${ }^{*} P<0.05$ Gp III $v s$ I and II

$\dagger P<0.05$ Gp III vs I

$\ddagger P<0.05$ Gp III vs II

cords, nor observed position of the vocal cords (Table III). In group I, the vocal cords were closed in $6 \%$ of patients. However, in all of these patients intubation was achieved by gently advancing the nasal tube with a Magill forceps because the vocal cords were not tightly apposed. In $2 \%$ of patients, in groups II and I, there was no exposure of the cords. Intubation in these patients was achieved by lifting the epiglottis with McGill forceps to facilitate visualization of the cords and then advancing the nasal tube through the cords. There was a higher incidence of movement on intubation in patients in Group I $(37.5 \%)$ than in Group III $(8.3 \%), P<0.001$ or in Group II $(2 \%), P<$ 0.05 . Movement was confined to slight flexion/withdrawal of either the upper an/or lower limbs. There was no coughing, diaphragm or chest movement in either group. There were also no differences among groups in supplementary propofol requirements for 
TABLE V Summary of intubation conditions with varying combinations of propofol with or without short acting opioids as reported in previous studies (Alf=alfentanil; Remi=remifentanil; Sux=succinylcholine).

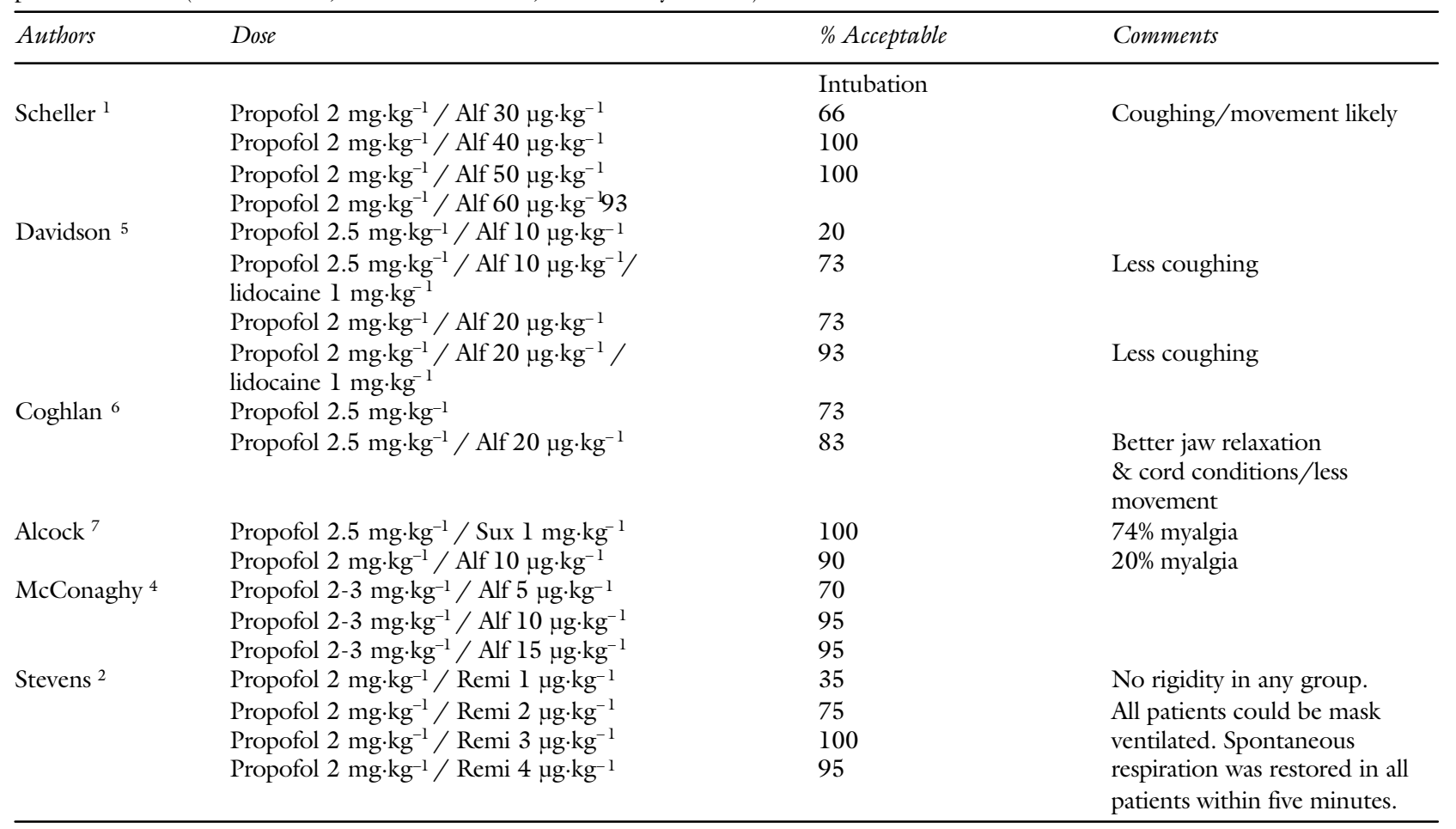

intubation. No complications of airway management were noted in any group and nasal intubation was possible in all patients. Blood pressure and heart rate remained within $\pm 20 \%$ of baseline in all three groups.

In the PAR, there were no differences between groups in the incidence, severity (VAS scores) and distribution of myalgia. No patient reported shoulder or abdominal myalgia while in the PAR.

At home, there were differences in the severity of myalgia (VAS score) among groups on days one to four but not on day five. Group III patients had significantly higher median VAS myalgia scores than Group II on days one to four and Group I on days one and two. (Table IV). The incidence of myalgias at home by muscle group is summarized in the Figure. There was a higher incidence of neck myalgia in Group III (72\%) compared with Group II (44\%) and Group I $(41 \%), P<0.05$. There was a higher incidence of chest myalgia in Group III (21\%) compared to Group II $(2.6 \%)$ and Group I $(5 \%), P<0.01$. There was a higher incidence of upper back myalgia in Group III (30\%) than in Group I $(7.7 \%), P=0.01$. Abdominal myalgias were more common in Group III $(23 \%)$ than in Group II $(2.6 \%), P=0.006$. The occurrence of upper and lower limb myalgia did not differ among groups.
Power analysis after the study confirms that, with respect to myalgia, the study has a power of $>90 \%$.

Discussion

In this study, we found that tracheal intubation in healthy young outpatients after $2.5 \mathrm{mg} \cdot \mathrm{kg}^{-1}$ propofol and $20 \mu \mathrm{g} \cdot \mathrm{kg}^{-1}$ alfentanil was associated with satisfactory intubating conditions as judged by measures such as jaw mobility, ability to mask ventilate, exposure of the vocal cords, and position of the vocal cords. However, movement of the limbs on intubation occurred in a considerable number $(37 \%)$ of patients. Myalgia was present in some patients in all three groups for five days after surgery, but the median scores were zero by day three in Groups I and II and by day four in Group III. Avoidance of succinylcholine reduced the incidence and severity of myalgia on the first two days after surgery. Administration of succinylcholine was beneficial in reducing limb movement on intubation and the problem of closed cords, which occurred in 6\% of Group I patients. Precurarisation with $3 \mathrm{mg}$ d-tubocurarine was beneficial in reducing the severity of succinylcholine myalgias. This effect was for evident for four days after surgery and may suggest that d-tubocurarine has a therapeutic effect on all myalgias, whether they are associated with succinylcholine or not. The anatomical 
distribution of myalgias was also different between groups. Neck, chest, upper back and abdominal myalgias were significantly more common in patients intubated with succinylcholine alone.

Intubation of the trachea without the use of neuromuscular blockade has been well studied (Table V). ${ }^{1,2,4-7}$ Propofol alone or in combinations with small $\left(<40 \mu \mathrm{g} \cdot \mathrm{kg}^{-1)}\right.$ doses of alfentanil was more likely to be associated with suboptimal intubating conditions. ${ }^{1,4-7}$ Similarly, propofol in conjunction with $<3 \mu \mathrm{g} \cdot \mathrm{kg}^{-1}$ of remifentanil was associated with suboptimal intubating conditions. ${ }^{2}$ However, these studies employed multiple anesthesiologists for intubation. In the present study we controlled for inter-observer variability by employing one blinded anesthesiologist for airway assessment and intubation. We found suboptimal intubating conditions in $37.5 \%$ of patients in Group 1 (propofol/alfentanil alone) due to limb movement. However, unlike previous studies all patients in all three groups were successfully intubated. The principal reasons for suboptimal intubating conditions when employing propofol/ alfentanil without muscle relaxants for intubation are limb movement, coughing and poor view. In the present study, we did not observe coughing during intubation. This is an important consideration because coughing may predispose to an increased incidence of postoperative sore throat. The present study was not designed to evaluate the problem of postoperative sore throat - future studies need to address this issue. The use of alfentanil in doses > $20 \mu \mathrm{g} \cdot \mathrm{kg}^{-1}$ appears to overcome movement during intubation. ${ }^{1,4-7}$ The adjunctive administration of lidocaine $1 \mathrm{mg} \cdot \mathrm{kg}^{-1}$ appears to reduce coughing during intubation. ${ }^{5}$ Poor visibility during laryngoscopy can be subjective and is dependent on the experience of the anesthesiologist. However, additional administration of muscle relaxants improves visibility and success rate but comes at a price - myalgia. ${ }^{7}$

The incidence of myalgia is $>70 \%$ with the use of succinylcholine alone as shown in this and previous studies. ${ }^{7}$ Coadminstration of alfentanil lowered the incidence of myalgia to approximately $20 \%$ for most muscle groups but was still approximately $50 \%$ for the neck muscles. This protective effect of alfentanil has been confirmed by previous studies where the incidence of succinylcholine induced myalgias was reduced from $74 \%$ to $20 \%$ with the adjunctive administration of $10 \mu \mathrm{g} \cdot \mathrm{kg}^{-1}$ alfentanil. ${ }^{7}$ Precurarisation with $3 \mathrm{mg}$ of d-tubocurarine was better than alfentanil in reducing the incidence and severity of myalgias. The incidence of myalgia was reduced, at best, to $<10 \%$ and, at worst, to $<50 \%$ by pretreatment with tubocurarine. Our results with tubocurarine are comparable to previous studies. ${ }^{7}$ However, unlike previous studies 9 we have shown a differential effect on muscle groups. Myalgia of the neck, chest, upper back and abdomen was increased with the use of succinylcholine alone. Avoidance of succinylcholine by intubation with propofol/alfentanil reduced the incidence of of the neck myalgia, chest and upper back but not the abdomen. Pretreatment with tubocurarine reduced myalgias of the neck, chest and abdomen but not the upper back. In addition, unlike previous studies, ${ }^{7-9}$ that followed patients for a maximum of 48 and $72 \mathrm{hr}$ after surgery, we followed patients daily for five days. Such a detailed follow-up of outpatients has not been previously reported and, we have demonstrated that tubocurarine has a beneficial effect that is seen for four days after surgery. The severity of myalgia as judged by VAS scores was reduced by tubocurarine on postoperative days one to four inclusive. We have also demonstrated that myalgias occur in outpatients who are intubated without muscle relaxants. The incidence varies according to muscle group and can range from $<10 \%$ to $40 \%$ and, these myalgias may be present for up to five days after surgery in some patients.

The incidence of postoperative myalgia in outpatients varies from 1.5 to $89 \%$ as reported in earlier studies. ${ }^{10}$ Myalgias appears to occur even if succinylcholine is replaced with non-depolarizing muscle relaxants. ${ }^{8-10}$ Myalgias can be very debilitating and $50 \%$ and $23 \%$ of outpatients receiving succinylcholine and atracurium respectively had to stay in bed or take analgesics to obtain relief. ${ }^{10}$ The variable incidence of myalgias in different studies appears to be a function of type of surgical population studied, duration of follow up and type of follow up. Our study provides comprehensive follow up data of outpatients that allows meaningful conclusions to be drawn with respect to avoiding muscle relaxants in outpatient and substituting them with short acting opioids. We have demonstrated that when succinylcholine is avoided in a propofol/alfentanil induction-intubation technique, there is a beneficial effect in terms of a lower incidence and severity of postoperative myalgia. One limiting factor in our study was that we did not include a study group in which a non-depolarizing muscle relaxant was substituted for succinylcholine. However, this would not be reflective of the practice in our daycare unit and we did not have strong evidence from previous studies to include such a group.

With respect to the $6 \%$ incidence of closed cords in Group I, it could be argued that even though there was no difference in intubating conditions among the three groups, our study did not have sufficient power to detect a difference. Unfortunately, it would require 
a sample size of at least 250 patients per group to show a decrease in incidence of closed cords to $4 \%$ in the treatment group with sufficient power. Such a large sample size is too prohibitive to make it worth performing a study that may reduce the low incidence of closed cords to an even lower level with succinylcholine. From an ethical perspective it would also be questioned because the risk of myalgia would be considerable as already shown.

In conclusion, the use of propofol / alfentanil for intubation was found to be associated with satisfactory and successful intubation although a significant number of patients exhibited some limb movement during intubation. This technique was also associated with a lower incidence and severity of postoperative myalgia for two days. Succinylcholine administration abolished limb movement during intubation. The $6 \%$ incidence of closed cords in the propofol/alfentanil group was also avoided with the use of succinylcholine. These benefits of succinylcholine were associated with significant increase in postoperative myalgias. Precurarisation with tubocurarine was also beneficial in reducing succinylcholine-induced myalgia. Patients who received dtubocurarine had no more myalgias than those who did not have succinylcholine. Therefore, while intubation can be performed without muscle relaxants, the choice of precurarisation and subsequent succinylcholine produce optimal intubating conditions and minimal myalgia. It is suggested that the decision to avoid muscle relaxants for intubation should be based upon the experience of the anesthesiologist and that a muscle relaxant of choice should be readily available in case laryngoscopy is found to be suboptimal. Future areas to study include the use of inhalational agents to deepen anesthesia prior to intubation without muscle relaxants, the issue of sore throat, and the potential role for future ultra short acting non depolarizing muscle relaxants.

\section{References}

1 Scheller MS, Zornow MH, Saidman LJ. Tracheal intubation without the use of muscle relaxants: a technique using propofol and varying doses of alfentanil. Anesth Analg 1992; 75: 788-93.

2 Stevens JB, Wheatley $L$. Tracheal intubation in ambulatory surgery patients: using remifentanil and propofol without muscle relaxants. Anesth Analg 1998; 86: 45-9.

3 Mallampatti SR, Gatt SP, Gugino LD, et al. A clinical sign to predict difficult tracheal intubation: a prospective study. Can Anesth Soc J 1985; 32: 429-34.

4 McConaghy P, Bunting HE. Assessment of intubating conditions in children after induction with propofol and varying doses of alfentanil. Br J Anaesth 1994; 73: 596-9.
5 Davidson JAH, Gillespie JA Tracheal intubation after induction of anaesthesia with propofol, alfentanil and i.v. lignocaine. Br J Anaesth 1993; 70: 163-6.

6 Coughlan SFE, McDonald PF, Csepregi G Use of alfentanil with propofol for nasotracheal intubation without neuromuscular block. Br J Anaesth 1993; 70: 89-91.

7 Alcock R, Peachey T, Lynch M, McEwan T. Comparison of alfentanil with suxamethonium in facilitating nasotracheal intubation in day case anaesthesia. $\mathrm{Br} \mathrm{J}$ Anaesth 1993; 70: 34-7.

8 Smith I, Ding $\Upsilon$, White PF. Muscle pain after outpatient laparoscopy - influence of propofol versus thiopental and enflurane. Anesth Analg 1993; 76: 1181-4.

9 Zabl K, Apfelbaum JL. Muscle pain occurs after outpatient laparoscopy despite the substitution of vecuronium for succinylcholine. Anesthesiology 1989; 70: 408-11.

10 Trepanier CA, Broussean C, Lacerte L. Myalgia in outpatient surgery: comparison of atracurium and succinylcholine. Can J Anaesth 1988; 35: 255-9. 